\title{
ECG Body Surface Mapping Changes in Type 1 Diabetic Patients with and without Autonomic Neuropathy
}

\author{
S. PALOVÁ ${ }^{1}$, K. SZABO ${ }^{1}$, J. CHARVÁT ${ }^{1}$, J. SLAVÍČEK ${ }^{2}$, E. MEDOVÁ ${ }^{2}$, M. MLČEK ${ }^{2}$, \\ O. KITTNAR ${ }^{2}$ \\ ${ }^{1}$ Department of Medicine, Second Medical Faculty, Charles University, Prague, Czech Republic, \\ ${ }^{2}$ Institute of Physiology, First Medical Faculty, Charles University, Prague, Czech Republic
}

Received November 13, 2008

Accepted April 2, 2009

On-line June 19, 2009

\begin{abstract}
Summary
ECG body surface mapping (BSM) parameters in patients with diabetes mellitus Type 1 (DM1) are significantly different comparing to healthy non-diabetic subjects. Hypothesis that these changes are more pronounced in DM1 patients with autonomic neuropathy (AN) was tested. The parameters of BSM were registered by diagnostic system Cardiag 112.2 in 54 DM1 patients including 25 with AN and 30 control subjects. AN was diagnosed according to Ewing criteria when two or more Ewing tests were abnormal. In classic 12-lead ECG the heart rate was increased, QRS and QT shortened $(p<0.01)$ and $\mathrm{QT}_{C}$ prolonged in DM1 patients. The VCG measurement of QRS-STT angles and spatial QRS-STT angle showed non-significant differences. The absolute values of maximum and minimum in depolarization and repolarization isopotential, isointegral, isoarea maps were significantly different in DM1 patients in comparison with controls $(p<0.01)$. The changes were more pronounced in DM1 patients with $A N$ than in DM patients without AN $(p<0.05)$. The QT duration measured in 82 leads of thorax was significantly shortened in 68 leads of both groups of DM 1 patients $(p<0.01)$ when compared with controls. In 34 of them this shortening was more pronounced in DM1 patients with AN than in DM1 patients without AN $(p<0.05)$. The results showed that the method of ECG BSM is capable to confirm the presence of autonomic neuropathy in diabetic patients.
\end{abstract}

\section{Key words}

Diabetes mellitus type 1 - Autonomic neuropathy - ECG Body Surface Mapping

\section{Corresponding author}

O. Kittnar, Institute of Physiology, First Medical Faculty, Charles University, Albertov 5, 12800 Prague 2, Czech Republic. E-mail: otomar.kittnar@lf1.cuni.cz

\section{Introduction}

Diabetes mellitus can be complicated by autonomic neuropathy even in young DM1 patients (Alberti et al. 1978, Alberti and Zimmet 1989, Beckman et al. 2002). The relatively increased sympathetic control in patients with autonomic neuropathy is associated with the higher risk of sudden cardiac death (Alberti et al. 1978, Alberti and Zimmet 1989). In these patients the heart rate is accelerated and cardiac response to the different stimuli is pathological as far as autonomic neuropathy produces some abnormalities in heart electrical field (Ruttkay-Nedecky 2001, Javorka et al. 2005). In our previous work we found the differences in some parameters of heart electrical field in DM1 patients in comparison with controls (Žd'árská et al. 2007). In the present study we tested hypothesis that autonomic neuropathy is associated with more pronounced changes on body surface mapping in the DM1 patients. The preliminary results have been published in abstract form (Palová et al. 2007).

\section{Methods}

The first type diabetic patients (DM1) were recruited in diabetic outpatient department of Medical department of Faculty Hospital Prague Motol. Fifty-four diabetic patients (31 men, 23 women) and 30 controls (11 men, 19 women) participated in the study (Table 1). In DM1 20 men and in DM1 with AN 11 men were present. The parameters of heart electric field were evaluated together for men and women. 


\section{Inclusion criteria:}

Type 1 diabetes mellitus

Age: between 18-50 years

Twelve leads ECG: within normal limits

\section{Exclusion criteria:}

Another drug treatment than insulin

Signs of retinopathy

Presence of microalbuminuria

Serum creatinine or urea elevation

Any 12 lead ECG abnormalities

Another disease than Type 1 diabetes mellitus

In diabetic patients the duration of DM1 was recorded. DM1 was diagnosed by the increased fasting blood sugar, low C-peptide, and positive findings of glutamic acid decarboxylase 65 (anti-GAD65) or/and to autoantibodies to islet cells (anti-ICA). The long-term metabolic compensation of diabetic patients was evaluated by HbA1c level according to IFCC (Pickup and Williams 2003). The average total daily insulin dosage was also recorded.

Autonomic diabetic neuropathy (AN) was diagnosed according to Ewing tests examined and evaluated according to previously published protocols (Alberti et al. 1978, Alberti and Zimmet 1989). Cardiovascular tests have been developed which indicate the presence or absence of autonomic neuropathy.

Table 1. The characteristics of controls and diabetic patients Type 1 (DM1) with or without autonomic neuropathy (mean \pm S.D.).

\begin{tabular}{|c|c|c|c|c|}
\hline & $\begin{array}{c}\text { Controls } \\
(\mathbf{n}=\mathbf{3 0})\end{array}$ & $\begin{array}{c}\text { DM1 } \\
\text { without AN } \\
(n=29)\end{array}$ & $\begin{array}{c}\text { DM1 } \\
\text { with AN } \\
(n=25)\end{array}$ & $\mathbf{p}$ \\
\hline Age (years) & $29.60 \pm 3.22$ & $32.59 \pm 5.55$ & $32.24 \pm 5.77$ & NS \\
\hline $\begin{array}{l}\text { DM1 } \\
\text { duration } \\
\text { (years) }\end{array}$ & - & $13.23 \pm 7.82$ & $13.82 \pm 6.64$ & NS \\
\hline HbAlc (\%) & - & $6.41 \pm 1.28$ & $6.96 \pm 1.11$ & NS \\
\hline $\begin{array}{l}\text { Insulin } \\
\text { dosage } \\
\text { (units/day) }\end{array}$ & - & $42.44 \pm 10.71$ & $46.18 \pm 11.47$ & NS \\
\hline$B M I\left(\mathrm{~kg} / \mathrm{m}^{2}\right)$ & $24.30 \pm 2.98$ & $23.44 \pm 2.80$ & $24.40 \pm 2.32$ & NS \\
\hline
\end{tabular}

AN - autonomic neuropathy, DM1 - Type 1 diabetes mellitus, HbA1c - glycolated hemoglobin, BMI - body mass index.
The following five autonomic function tests have been performed. The patients with at least two abnormal tests were labeled to suffer from AN (Alberti et al. 1978, Alberti and Zimmet 1989).

\section{Ewing autonomic function tests:}

1) Heart rate variation of deep breathing abnormal $<10$ beats/min

2) Heart rate increase on standing at $15 \mathrm{~s}-$ abnormal $<12$ beats/min

3) Heart rate increase on standing, 30:15 ratio abnormal $<1.00$

4) Valsalva ratio - abnormal $<1.2$

5) Postural systolic pressure fall at $2 \mathrm{~min}-$ abnormal $>30 \mathrm{~mm} \mathrm{Hg}$

The electrocardiogram (ECG), vectorcardiogram (VCG) and body surface isopotential, isointegral and isoarea maps (BSM) were registered altogether using the diagnostic system CARDIAG 112.2 (Slavíček et al. 2001, Kittnar and Št'ovíček 1993) one hour after a light breakfast and an insulin application in diabetic patients in the morning hours. Healthy control subjects were also examined one hour after breakfast. 201 parameters of heart electrical field were registered in controls, DM1 patients without and with AN.

Heart rate, duration of PQ, QRS, QT and QTc intervals were recorded and evaluated by 12 leads ECG.

In the VCG evaluation, the Frank orthogonal lead system was used (Frank 1956). The depolarization, repolarization isopotential maps (DIPM, RIMP), isointegral depolarization and repolarization maps (DIIM, RIIM) and their maximum and minimum were recorded and evaluated by ECG body surface potential maps (BSM). Depolarization isoarea maps, their maximum and minimum in $\mu \mathrm{Vs}$ (isointegral maps from the beginning of QRS until 40 ms - DIAM max 40, DIAM min 40) and repolarization areas and their maximum and minimum in $\mu \mathrm{Vs}$ (isointegral maps from the point $\mathrm{J}$ to $40 \mathrm{~ms}$ - RIAM $\max 40$ and RIAM min 40) were examined as well as isointegral minimum (Q-IIM), amplitude (IPMAM-Q) of $\mathrm{Q}$ wave as and QT duration in the chest electrodes. Activation time (ICHVAT in ms) was measured between the beginning of depolarization in an orthogonal lead and the $\mathrm{R}$ wave in the individual chest leads. The QT duration was measured in 85 thoracic leads.

All diabetic patients and control subjects signed informed consent forms prior to their inclusion in the study. The local ethical committee accepted the study 
Table 2. Heart rate, $\mathrm{PQ}, \mathrm{QRS}, \mathrm{QT}, \mathrm{QTC}$ and R/R duration in controls and DM1 patients with or without autonomic neuropathy measured by classic 12-leads ECG.

\begin{tabular}{lccccc}
\hline Parameter & $\begin{array}{c}\text { Controls } \\
(\mathbf{n = 3 0 )}\end{array}$ & $\begin{array}{c}\text { DM1 without AN } \\
(\mathbf{n = 2 9 )}\end{array}$ & $\begin{array}{c}\text { DM1 with AN } \\
(\mathbf{n = 2 5})\end{array}$ & $\begin{array}{c}\mathbf{p} \\
\mathbf{M}-\mathbf{W}\end{array}$ & $\begin{array}{c}\mathbf{p} \\
\mathbf{K}-\mathbf{W}\end{array}$ \\
\hline Heart rate $\left(\mathrm{min}^{-1}\right)$ & $73.97 \pm 1.79$ & $82.24 \pm 2.54^{*}$ & $92.24 \pm 3.00^{* *}$ & $<0.01$ & 0.000 \\
$P Q(\mathrm{~ms})$ & $153.93 \pm 5.81$ & $142.82 \pm 3.59$ & $154.08 \pm 10.08$ & $\mathrm{NS}$ & 0.743 \\
$Q R S(\mathrm{~ms})$ & $87.60 \pm 2.28$ & $78.62 \pm 1.51^{*}$ & $75.52 \pm 1.63^{* *}$ & $<0.01$ & 0.001 \\
$Q T(\mathrm{~ms})$ & $376.53 \pm 4.05$ & $352.24 \pm 5.90^{* *}$ & $350.72 \pm 10.08^{* *}$ & $<0.01$ & 0.000 \\
$Q T c(\mathrm{~ms})$ & $404.53 \pm 12.08$ & $424.03 \pm 16.31$ & $431.40 \pm 12.66$ & $\mathrm{NS}$ & 0.241 \\
$R R(\mathrm{~ms})$ & $753.29 \pm 22.28$ & $751.48 \pm 23.05$ & $668.09 \pm 25.89 *$ & $<0.05$ & 0.014 \\
\hline
\end{tabular}

DM1 - type 1 diabetes mellitus, AN - autonomic neuropathy, $* \mathrm{p}<0.05 ; * * \mathrm{p}<0.01$ in comparison of controls and diabetic patients; comparison of heart rate and QRS duration in DM 1 patients with or without AN (second and third column) $-p<0.05 ; p M-W-M a n n-$ Whitney test; $\mathrm{p} \mathrm{K-W}$ - test Kruskal-Wallis for all three groups. Data are means \pm S.E.M.

Table 3. VCG QRS-STT angles (expressed in degrees) in frontal, transversal, left sagital planes and the spatial QRS-STT angle.

\begin{tabular}{|c|c|c|c|c|}
\hline Parameter & $\begin{array}{l}\text { Controls } \\
(\mathbf{n}=\mathbf{3 0})\end{array}$ & $\begin{array}{l}\text { DM1 without AN } \\
\qquad(n=29)\end{array}$ & $\begin{array}{l}\text { DM1 with AN } \\
\qquad(n=25)\end{array}$ & $\underset{\mathbf{K}-\mathbf{W}}{\mathbf{p}}$ \\
\hline \multicolumn{5}{|l|}{ QRS-STT angle } \\
\hline \multicolumn{4}{|l|}{ QRS-STT angle } & 0.923 \\
\hline \multicolumn{4}{|l|}{ QRS-STT angle } & 0.128 \\
\hline (left sagital plane) & $-43.77 \pm 4.13$ & $-62.34 \pm 15.26$ & $-64.60 \pm 9.27$ & 0.092 \\
\hline \multicolumn{5}{|l|}{ QRS-STT spatial } \\
\hline angle & $44.10 \pm 6.33$ & $59.24 \pm 6.17$ & $49.12 \pm 5.02$ & 0.094 \\
\hline \multicolumn{5}{|l|}{ QRS axis } \\
\hline in frontal plane & $38.30 \pm 6.84$ & $37.66 \pm 5.89$ & $38.12 \pm 5.41$ & 0.833 \\
\hline
\end{tabular}

For more detailed description see Table 2. Data are means \pm S.E.M.

protocol with respect to the 1964 Declaration of Helsinki.

\section{Statistical evaluation}

The mean value, standard deviation (S.D.) and standard error of mean (S.E.M.) of the measured parameters were calculated. T-test and $\chi^{2}$ test were used for evaluation of basal characteristics. Kruskal-Wallis test was used for comparison of 12-leads ECG, vectorcardiogram and BSM parameters of all three studied groups (diabetic patients with or without AN and healthy control subjects). The non-parametric MannWhitney test was used for separate comparison of 12-leads ECG, vectorcardiogram and BSM parameters of 2 diabetic groups. $\mathrm{p}<0.05$ value was considered to be significant.

\section{Results}

The number of controls and diabetic patients with or without $\mathrm{AN}$ as well as the parameters of the compensation and treatment of DM1 are summarized in Table 1. No significant changes in these characteristics were present among the groups. Out of twenty-five patients with diagnosis of $\mathrm{AN}$, twenty-one presented a score of 2 and the remaining four patients a score of 3 in pathological Ewing tests.

The results of 12 leads ECG are shown in Table 2. Comparing only two groups of patients with DM1, the significant difference was detected for heart rate which was faster in patients with $\mathrm{AN}(\mathrm{p}<0.05)$ and R-R shortened $(p<0.05)$. The duration of $Q R S$ was 
Table 4. The selected parameters of BSM, the significant differences between DM1 patients with or without AN, and control subjects.

\begin{tabular}{|c|c|c|c|c|}
\hline Parameter & $\begin{array}{c}\text { Controls } \\
(\mathbf{n}=\mathbf{3 0})\end{array}$ & $\begin{array}{l}\text { DM1 without AN } \\
(n=29)\end{array}$ & $\begin{array}{l}\text { DM1 with AN } \\
\qquad(n=25)\end{array}$ & p K-W \\
\hline DIPMmax10 $(\mu \mathrm{V})$ & $100.67 \pm 10.92$ & $147.21 \pm 10.95^{* *}$ & $145.24 \pm 21.73$ & 0.001 \\
\hline DIPMmax30 $(\mu V)$ & $716.60 \pm 55.41$ & $1016.20 \pm 68.17 * *$ & $993.60 \pm 45.80$ & 0.005 \\
\hline DIPMmax50 $(\mu V)$ & $1051.17 \pm 98.93$ & $747.52 \pm 69.36$ & $679.64 \pm 83.16^{*}$ & 0.015 \\
\hline$D I P M \min 10(\mu \mathrm{V})$ & $-48.50 \pm 4.06$ & $-66.24 \pm 7.04 *$ & $-65.40 \pm 5.64$ & 0.020 \\
\hline$D I P M \min 20(\mu \mathrm{V})$ & $-150.80 \pm 21.27$ & $-239.03 \pm 41.11$ & $-238.10 \pm 38.31^{*}$ & 0.017 \\
\hline$D I P M \min 30(\mu V)$ & $-370.13 \pm 61.07$ & $-791.86 \pm 123.92 * *$ & $-801.04 \pm 113.40^{* *}$ & 0.000 \\
\hline$D I P M \min 40(\mu V)$ & $-792.43 \pm 102.80$ & $-1502.14 \pm 158.60 * *$ & $-1382.67 \pm 155.70 * *$ & 0.000 \\
\hline $\operatorname{DIIMmin}\left(\mu V_{s}\right)$ & $-31.48 \pm 2.71$ & $-46.21 \pm 4.28^{*}$ & $-38.17 \pm 3.61$ & 0.026 \\
\hline$D I A M \max 40(\mu V s)$ & $14.11 \pm 1.05$ & $19.84 \pm 1.31^{*}$ & $19.14 \pm 1.94^{* *}$ & 0.004 \\
\hline$D I A M \min 40(\mu V s)$ & $-6.96 \pm 0.98$ & $-14.15 \pm 2.13 * *$ & $-12.75 \pm 2.16^{* *}$ & 0.000 \\
\hline$R I P M \max 10(\mu \mathrm{V})$ & $144.67 \pm 21.09$ & $114.45 \pm 16.46$ & $84.6 \pm 18.65^{*}$ & 0.004 \\
\hline RIPMmin50 $(\mu \mathrm{V})$ & $-278.10 \pm 131.14$ & $-127.26 \pm 11.64$ & $-100.38 \pm 9.48 *$ & 0.026 \\
\hline RIPMmin60 $(\mu V)$ & $-316.67 \pm 120.94$ & $-156.12 \pm 13.31$ & $-130.00 \pm 11.56^{* *}$ & 0.004 \\
\hline RIPMmin70 $(\mu V)$ & $-354.80 \pm 110.53$ & $-188.52 \pm 16.19^{*}$ & $-157.62 \pm 12.63^{* *}$ & 0.001 \\
\hline RIPMmin80 $(\mu \mathrm{V})$ & $-326.13 \pm 103.28$ & $-178.50 \pm 16.02$ & $-157.80 \pm 11.76^{* *}$ & 0.005 \\
\hline$Q-I P M A M \min (\mu V)$ & $-625.50 \pm 12.80$ & $-850.34 \pm 17.85$ & $-866.83 \pm 19.29 *$ & 0.023 \\
\hline $\operatorname{ICHVAT}(\mathrm{ms})$ & $68.90 \pm 1.69$ & $62.72 \pm 1.25^{*}$ & $59.70 \pm 1.35^{* *}$ & 0.001 \\
\hline$Q-I I M \min (\mu V S)$ & $-14.86 \pm 1.04$ & $-21.96 \pm 2.63$ & $-24.02 \pm 2.58 *$ & 0.016 \\
\hline$Q S-I P M A M \min (\mu V)$ & $-557.12 \pm 50.60$ & $-772.17 \pm 98.92$ & $-843.08 \pm 82.30 *$ & 0.036 \\
\hline
\end{tabular}

DIPMmax, DIPMmin - maximum, minimum in depolarization isopotential map $(\mu \mathrm{V})$, DIIMmin - minimum in depolarization isointegral map ( $\mu \mathrm{Vs}$ ), DIAMmax 40, DIAMmin 40 - maximum, minimum in depolarization isoarea map from the beginning of QRS to $40^{\text {th }}$ ms of depolarization ( $\mu \mathrm{Vs})$, RIPMmax, RIPMmin - maximum, minimum in repolarization isopotential map ( $\mu \mathrm{V})$, Q-IPMAM - amplitude of $\mathrm{Q}$ wave $(\mu \mathrm{V})$, ICHVAT - activation time between the onset of electrical activation registered by orthogonal leads $x, y, z$ and the thoracic surface ECG (ms), Q-IIM - minimum in isointegral map of Q-wave $(\mu \mathrm{Vs})$, QS-IPMAM - amplitude of Q and $\mathrm{S}$ wave $(\mu \mathrm{V})$, * $\mathrm{p}<0.05$, $* * \mathrm{p}<0.01$ in comparison with controls; $\mathrm{p} \mathrm{K-W}-$ Kruskal-Wallis test for all three group. Data are means \pm S.E.M.

significantly shortened in DM1 patients with AN patients compared to controls $(\mathrm{p}<0.01)$. The shortening of QRS was more pronounced in DM1 patients with $\mathrm{AN}(\mathrm{p}<0.01)$ than in DM1 patients without AN $(p<0.05)$ when compared with controls. The duration of QT was shortened in both groups of diabetic patients due to the increase of heart rate. The $\mathrm{QT}_{\mathrm{C}}$ was prolonged in both groups of diabetic patients, but non-significantly (probably due to the wide range of variation in DM1 patients).

The planar QRS-STT angles in VCG changed in a different way in both DM1 groups of patients (Table 3). The QRS axis in frontal plane was unchanged in comparison with controls, similarly as the QRS-STT angle in frontal plane.

The QRS-STT angle in transversal (horizontal) plane was more opened only in DM1 patients without AN, while in left sagital plane the angle was opened in both groups. The spatial angle was opened by in a more pronounced way in DM1 without AN than in DM1 with AN. The differences were not statistically significant (Mann-Whitney), the result of Kruskal-Wallis test was significant for the value of left sagital plane angle and spatial angle (Table 3).

The parameters of heart electric field in the diabetic patients (both without or with $\mathrm{AN}$ ) and control subjects during BSM measurement are summarized in Table 4. The maximum in depolarization of isopotential maps (DIPMmax) was more positive until the $30^{\text {th }} \mathrm{ms}$ and more negative from the $50^{\text {th }} \mathrm{ms}$. The minimum (DIPMmin) was more negative until the $40^{\text {th }} \mathrm{ms}$ of the QRS. The repolarization isopotential map maximum (RIPMmax) was less positive in the $10^{\text {th }} \mathrm{ms}$ and minimum (RIPMmin) less negative from $50^{\text {th }}$ to $80^{\text {th }} \mathrm{ms}$ from the beginning of the point $\mathbf{J}$ (terminal part of the QRS). The changes in DIPM maps were confirmed by 
measurement of depolarization isointegral and isoarea maps maximum and minimum (DIIM, DIAM). The amplitude of $\mathrm{Q}$ and $\mathrm{S}$ wave were more negative (Q-IPMAMmin, QS-IPMAMmin) similarly as the minimum in the isointegral map of the $Q$ wave (Q-IIMmin) in DM patients than in controls. The activation time (ICHVAT) was faster in DM1 patients due to the increased heart rate (Table 4).

In 12 out of 19 parameters (DIPMmax50, DIPMmin20, DIAMmax40, RIPMmax10, RIPMmin 50, 60, 70, 80, Q-IPMAMmin, Q-IIMmin, QS-IPMAMmin, ICHVAT) the DM1 patients with AN showed the more pronounced changes $(\mathrm{p}<0.01)$, than DM1 patients without AN $(p<0.05)$ in comparison with controls. On the other hand, the changes of four parameters (DIPMmax10, 30, DIPMmin10, DIIMmin) were more pronounced in DM1 without AN than in DM1 patients with AN $(p<0.05$, Table 4). The values of three parameters (DIPMmin30, 40, DIPMmin40) were non-significantly different in both groups of DM patients (Table 4), but significantly different in comparison with controls $(\mathrm{p}<0.01)$.

In 68 thoracic surface leads out of 82 measured the QT duration was significantly shortened in the both groups of DM1 patients when compared with controls. In 34 leads the QT shortening was more pronounced in DM1 patients with $\mathrm{AN}(\mathrm{p}<0.01)$ than in DM1 patients without AN $(p<0.05)$. In 34 other leads the shortening of QT duration was not different in the DM1 patients with and without AN in comparison with controls. In the resting 14 leads the significant shortening of the QT duration $(p<0.01)$ was observed only in DM1 patients with AN and not in DM 1 patients without AN (data not shown).

\section{Discussion}

The present work showed the differences in parameters of heart electric field in DM1 patients in comparison with the controls: acceleration of heart rate, shortening of RR, QRS and QT intervals. Depolarization and repolarization isopotential, isointegral, isoarea maps (the absolute values of maximum and minimum) were significantly changed. Fourteen parameters were different in comparison of controls and DM1 patients without AN, and twenty parameters were significantly different in comparison of controls and DM1 AN patients. The duration of QT measured in 80 surface thoracic leads was shortened in 68 of them in DM1 patients without AN, but in all 82 places in DM1 patients with AN. Comparison of two DM1 patient groups showed the more pronounced changes of some heart electric field parameters in DM1 AN patients than in patients without AN (Table 4). The present work confirmed our previous results in DM1 without AN (Žd'árská et al. 2007).

The statistically significant changes in localization of depolarization isopotential map minimum in $40^{\text {th }}$ and $50^{\text {th }} \mathrm{ms}$ (DIPMmin40, 50) were found. The values of minimum were placed two intercostal spaces lower in DM1 AN patients than in controls $(p<0.05)$.

Diabetes mellitus can be considered as a vascular disease because it causes both microvascular and macrovascular complications (Alberti et al. 1978, Kannel et al. 1986, Alberti and Zimmet 1989, Beckman et al. 2002, Pickup and Williams 2003). Cardiovascular disease accounts for at least $66 \%$ of deaths in diabetic patients. Due to the sensitive neuropathy, the coronary artery disease in diabetic patients is frequently asymptomatic (Alberti and Zimmet 1989, Langer et al. 1991, Paillole et al. 1995, Wackers et al. 2004). This fact underlines the importance of the sophisticated laboratory testing in diabetic patients, mainly stress myocardial SPECT and stress echocardiography, for diagnosis evaluation (Langer et al. 1991, Paillole et al. 1995, Wackers et al. 2004). Twelve leads resting ECG can be within normal limits even in an advanced stage of coronary artery disease (Alberti and Zimmet 1989, Pickup and Williams 2003). In this respect, BSM might be useful tool in coronary ischemia detection (Green et al. 1985, Kittnar et al. 1993, Valouch et al. 2004) in asymptomatic diabetic patients. However, the changes due to diabetes itself must be defined first before the specific abnormalities for silent coronary ischemia are looked for on BSM in diabetic patients.

In our present study therefore the young first type diabetic patients with normal resting 12 leads ECG and without any clinically evident macrovascular complications have been evaluated. These patients represent group of subjects with very low probability of asymptomatic coronary artery disease (Alberti et al. 1978, Alberti and Zimmet 1989, Pickup and Williams 2003).

The parameters of VCG, QRS-STT angles, the spatial angle and QRS axis in frontal plane were non-significantly different in comparison with controls probably due to a small number of patients (Table 3). However, Kruskal-Wallis test showed the value near to the $5 \%$ signification level in spatial QRS-STT angle and in QRS-STT angle of frontal and left sagital plane 
opening angle. Similarly the height level of SD in Table 3 is due to the small number of patients. On the other hand, the similar results were obtained in frontal plane, i.e. no change in QRS axis deviation and small change in QRS-STT angle in both groups of DM 1 patients in comparison with controls (Table 3).

We have shown the significant changes in heart depolarization and repolarization as well as in activation time and amplitude of Q wave in the young DM1 patients comparing to healthy non-diabetic controls. As far as no diabetic patient was known to suffer from coronary artery disease and only some of them fulfilled the criteria for autonomic neuropathy the body surface mapping changes could be attributed to the specific influence of diabetes. Diabetic patients have fasting as well as postprandial hyperglycemia (Alberti et al. 1978, Alberti and Zimmet 1989, Pickup and Williams 2003). They are using more fatty acids and less glucose for cardiac muscle energy metabolism comparing to non-diabetic subjects (Pickup and Williams 2003). This could lead to some changes in cardiomyocyte membranes.

The comparison of DM1 patients with and without AN showed some different results in heart electric field parameters. The heart rate was significantly faster in DM1 patients with AN than in DM1 patients without AN, the R-R, QRS and QT intervals shortened more in DM1 with AN than in DM1 without AN.

DM1 patients with and without AN presented the similar changes of some parameters of heart electric field on BSM. However, several parameters of heart electric field on BSM were more significantly changed in DM1 patients with $\mathrm{AN}$ patients than without $\mathrm{AN}$ in comparison with controls.

The significant changes of depolarization and repolarization in body surface mapping seen in our young DM1 patients could be explained by the activation of adrenergic system. The changes of these parameters were more pronounced in DM1 patients with AN. The absence of any statistically significant differences of BSM when only two diabetic groups have been considered could be attributed to limited number of diabetic patients included into study. As far as autonomic neuropathy is associated with significantly increased sympathetic activity (Ruttkay-Nedecky 2001, Javorka et al. 2005), the results of our study are in favor of the idea that body surface changes in Type 1 diabetic patients are related to power of adrenergic activation.

The similar results of heart electric field parameters on body surface mapping were observed in depressive patients treated with the tricyclic antidepressants (Slavíček et al. 1998, Paclt et al. 2003). This observation could be important as far as it is known that among diabetic patients there is high incidence of depressive subjects (Pickup and Williams 2003).

In summary, our results confirmed the significance of body surface mapping changes in young DM1 patients. The presence of more pronounced changes in the heart electric field parameters in DM1 patients with AN than without AN when compared with controls, supports hypothesis that BSM changes in DM1 patients are associated with the augmentation of the adrenergic activation.

\section{Conflict of Interest}

There is no conflict of interest.

\section{Acknowledgements}

This work was partially supported by Grants GAUK 53/2004, GAAV 1ET201210527. The authors wish to thank to Assoc. Prof. Ljuba Bacharová for her kind remarks, to Dr. Eva Medová and to Mrs. Tereza Vavř́ková for registration and evaluation of parameters of heart electric field, for preparation and correction of manuscript, and to Mrs. Alena Dohnalová for the statistical measurements.

\section{References}

ALBERTI KG, ZIMMET PZ, DE FRONZO RA: International Textbook of Diabetes Mellitus. John Wiley \& Sons Ltd., Chichester 1978.

ALBERTI KG, ZIMMET PZ: The WHO Consultation, definition, diagnosis and classification of diabetes mellitus and its complications. Part I: Diagnosis and classiffication of diabetes mellitus. Provisional report WHO Consultation. Diabet Med 15: 539-553, 1989.

BECKMAN JA, CREAGER MA, LIBBY P: Diabetes and atherosclerosis: epidemiology, pathophysiology and management. JAMA 287: 2570-2578, 2002.

FRANK E: An accurate, clinically practical system for spatial vectorcardiography. Circulation 13: 737-749, 1956. 
GREEN LS, LUX RL, HAW CW: Effect of age, sex and body habitus on QRS and ST-T potential maps of 1100 normal subjects. Circulation 71: 244-253, 1985.

JAVORKA M, JAVORKOVÁ J, TONHAIZEROVÁ I, JAVORKA K: Parasympathetic versus sympathetic control of the cardiovascular system in young patients with type 1 diabetes mellitus. Clin Physiol Funct Imaging 25: 270274, 2005.

KANNEL WB, NEATON JD, WENWORTH D, THOMAS HC, STAMLER J, HULLEY SB, KJELSBERG MO: Overall and coronary heart disease mortality rates in relation to major risk factors in 325348 men screened for the MDFIT. Multiple Risk Factor Intervention Trial. Am Heart J 112: 825-836, 1986.

KITTNAR O, ŠŤOVÍČEK P: Contemporary body surface potential mapping in electrocardiology and its perspectives. Physiol Res 42: 141-143, 1993.

KITTNAR O, SLAVÍČEK J, VÁVROVÁ M, BARNA M, DOHNALOVÁ A, MÁLKOVÁ A, ASCHERMANN M, HUMHAL J, HRADEC J, KRÁL J.: Repolarization patterns of body surface potential maps (BSPM) in coronary artery disease. Physiol Res 42: 123-130, 1993.

LANGER A, FREEMAN MR, JOSSE RG, STEINER G, ARMSTRONG PW: Detection of silent ischemia in diabetes mellitus. Am J Cardiol 67: 1037-1038, 1991.

PACLT I, SLAVÍČEK J, DOHNALOVÁ A, KITZLEROVÁ E, PIŠVEJCOVÁ K: Electrocardiographic dosedependent changes in prophylactic doses of dosulepine, lithium and citalopram. Physiol Res 52: 311-317, 2003.

PAILLOLE C, RUIZ J, JULIARD JM, LEBLANC H, GOURGON R, PASSA P: Detection of coronary artery disease in diabetic patients. Diabetologia 38: 726-731, 1995.

PALOVÁ S, PELÍŠKOVÁ P, CHARVÁT J, SLAVÍČEK J, MLČEK M, MEDOVÁ E, KITTNAR O: ECG body surface mapping (BSM) in diabetic patients (type 1) with autonomic diabetic neuropathy. Physiol Res 56: 27P, 2007.

PICKUP JC, WILLIAMS SG: Textbook of Diabetes. Blackwell Publishing, Oxford, 2003.

RUTTKAY-NEDECKY I: The effect of the autonomic nervous system on the heart. Electrocardiographic evaluation: problems and concern. Cardiology 10: 42-48, 2001.

SLAVÍČEK J, PACLT I, HAMPLOVÁ J, KITTNAR O, TREFNÝ Z, HORÁČEK BM: Antidepressant drugs and heart electrical field. Physiol Res 47: 297-300, 1998.

SLAVÍČEK J, KITTNAR O, NOVÁK V, TREFNÝ ZM, HORÁČEK BM: ECG body surface isointegral and isoarea maps (BSM) in 60-years-old healthy humans. Sborn Lék 102: 369-374, 2001.

VALOUCH P, SLAVÍČEK J, TICHÝ JA, PETERKA Z, KITTNAR O, TROJAN S, TREFNÝ Z, NOVÁK V: Electrocardiographic body surface maps (BSM) in patients with ischemic heart disease examined by coronary angiography. Prague Medical Report (Sborn Lék) 105: 131-140, 2004.

WACKERS FJ, YOUNG LH, INZUCCHI SE, CHYUN DA, DAVEY JA, BARRET EJ, TAILLEFER R, WITTLIN SD, HELLER GU, FILIPCHUK N, ENGEL S, RATNER RE: Detection of silent myocardial ischemia in asymptomatic diabetic subjects, the DIAD study. Diabetes Care 27: 1954-1961, 2004.

ŽĎÁRSKÁ D, PELÍŠKOVÁ P, CHARVÁT J, SLAVÍČEK J, MLČEK M, MEDOVÁ E, KITTNAR O: ECG body surface mapping (BSM) in type 1 diabetic patients. Physiol Res 56: 403-410, 2007. 